\title{
Switching from premixed insulin to glargine-based insulin regimen improves glycaemic control in patients with type I or type 2 diabetes: a retrospective primary care-based analysis Peter Sharplin¹, Jason Gordon ${ }^{1}$, John R Peters ${ }^{2}$, Anthony P Tetlow ${ }^{1}$, Andrea J Longman ${ }^{1}$ and Philip McEwan*1
}

Address: ${ }^{1}$ CHKS Health Economics Unit, Health Park, Cardiff, UK and ${ }^{2}$ Department of Medicine, School of Medicine, Cardiff University, Cardiff, UK

Email: Peter Sharplin - info@chks.co.uk; Jason Gordon - jason.gordon@crc-limited.co.uk;

John R Peters - john.peters@cardiffandvale.wales.nhs.uk; Anthony P Tetlow - ttetlow@chks.co.uk; Andrea J Longman - alongman@chks.co.uk; Philip McEwan* - pmcewan@chks.co.uk

* Corresponding author

Published: 16 February 2009

Cardiovascular Diabetology 2009, 8:9 doi:10.1 186/1475-2840-8-9
Received: 4 December 2008

Accepted: 16 February 2009

This article is available from: http://www.cardiab.com/content/8/I/9

(c) 2009 Sharplin et al; licensee BioMed Central Ltd.

This is an Open Access article distributed under the terms of the Creative Commons Attribution License (http://creativecommons.org/licenses/by/2.0), which permits unrestricted use, distribution, and reproduction in any medium, provided the original work is properly cited.

\begin{abstract}
Background: Insulin glargine (glargine) and premixed insulins (premix) are alternative insulin treatments. This analysis evaluated glycaemic control in 528 patients with type I $(n=183)$ or type $2(n=345)$ diabetes, after switching from premix to a glargine-based regimen, using unselected general practice (GP) data.

Methods: Data for this retrospective observational analysis were extracted from a UK GP database (The Health Improvement Network). Patients were required to have at least 12 months of available data, before and after, switching from premix to a glargine-based regimen. The principal analysis was the change in $\mathrm{HbA}_{\mathrm{Ic}}$ after 12 months of treatment with glargine; secondary analyses included change in weight, bolus usage and total daily insulin dose. Inconsistent reporting of hypoglycemic episodes precludes reliable assessment of this outcome. Multivariate analyses were used to adjust for baseline characteristics and confounding variables.
\end{abstract}

Results: Both cohorts showed significant reduction in mean $\mathrm{HbA}_{\mathrm{Ic}} 12$ months after the switch: by $-0.67 \%(p<0.00 \mathrm{I})$ in the type I cohort and by $-0.53 \%(p<0.00 \mathrm{I})$ in the type 2 cohort (adjusted data). The size of $\mathrm{HbA}_{I c}$ improvement was positively correlated with baseline $\mathrm{HbA}_{I c}$; patients with a baseline $\mathrm{HbA}_{\mathrm{Ic}} \geq 10 \%$ had the greatest mean reduction in $\mathrm{HbA}_{\mathrm{Ic}}$, by $-\mathrm{I.7 \%}(\mathrm{p}<0.00 \mathrm{I})$ and $-1.2 \%$ $(\mathrm{p}<0.00 \mathrm{I})$, respectively. The proportion of patients receiving co-bolus prescriptions increased in the type I (mean $24.6 \%$ to $95.1 \%, \mathrm{p}<0.00 \mathrm{I}$ ) and type 2 (mean I6.2\% to $73.9 \%, \mathrm{p}<0.00 \mathrm{I}$ ) cohorts. There was no significant change in weight in either cohort. Total mean insulin use increased in type 2 diabetes patients (from $0.67 \pm 1.35 \mathrm{U} / \mathrm{Kg}$ to $0.88 \pm 1.33 \mathrm{U} / \mathrm{Kg}, \mathrm{p}<0.00 \mathrm{I}$ ) with a slight decrease in type I diabetes patients (from I.04 $\pm 2.5 \mathrm{I} \mathrm{U} / \mathrm{Kg}$ to $0.98 \pm 2.58 \mathrm{U} / \mathrm{Kg}, \mathrm{P}<0.00 \mathrm{I}$ ).

Conclusion: In everyday practice, patients with type I or type 2 diabetes inadequately controlled by premix insulins experienced significant improvement in glycaemic control over 12 months after switching to a glargine-based insulin regimen. These findings support the use of a basal-bolus glargine-based regimen in patients poorly controlled on premix. 


\section{Background}

Achieving the recommended target for glycaemic control (glycated haemoglobin $\left[\mathrm{HbA}_{1 \mathrm{c}}\right] 6.5 \%$ to $7.0 \%$ ) [1-7] in patients with type 1 or type 2 diabetes is essential for reducing the risk of serious diabetes-related complications [8-10]. In type 1 diabetes this can only be achieved with insulin therapy. For patients with type 2 diabetes, insulin therapy is indicated after failure to achieve glycaemic control despite increasingly aggressive treatment with oral antidiabetic drugs (OADs) that are prescribed in combination with lifestyle changes.

Of the available insulin preparations, premixed insulins (premix), combine fixed ratios of short- and intermediate acting insulins into a single formulation that are generally injected once or twice daily. In general, premix insulins do not mimic physiologic insulin profiles and a substantial proportion of patients have sub-optimal glycaemic control [11]. Insulin glargine (glargine, Lantus ${ }^{\circledast}$ ), a long-acting basal insulin analogue, available in the UK since 2002, has a prolonged and predictable absorption rate over 24 hours, without peak effects [12]. In insulin-naïve patients with type 2 diabetes, glargine treatment combined with $\mathrm{OADs}$ is associated with significantly lower $\mathrm{HbA}_{1 \mathrm{c}}$ levels and fewer episodes of symptomatic hypoglycaemia compared with premix [13].

For patients who are inadequately controlled with premix, switching to a glargine-based regimen may offer advantages in terms of glycaemic control, tolerability and patient satisfaction with treatment [14-16]. In a retrospective sub-analysis of the AT.LANTUS (A Trial comparing Lantus Algorithms to achieve Normal blood glucose Targets in subjects with Uncontrolled blood Sugar with type 2 diabetes mellitus) study [16], including 686 patients with type 2 diabetes taking premix at baseline, poorly controlled patients who switched to glargine \pm OADs/prandial insulin showed significantly improved glycaemic control and a low incidence of severe hypoglycaemia after 6 months on treatment. Consistent with these findings, a 12-week observational study [14] showed that patients with type 2 diabetes who switched from premix to glargine plus $\mathrm{OAD}$ showed significant improvement in mean $\operatorname{HbA}_{1 \mathrm{c}}(-1.1 \pm 1.0 \%, \mathrm{p} \leq 0.001)$ and reduction in body weight $(-1.5 \pm 3.3 \mathrm{~kg}, \mathrm{p} \leq 0.001)$. However, whether these benefits extend to both type 1 and type 2 diabetes patients in routine clinical practice has yet to be investigated. Therefore, this retrospective analysis was performed to evaluate the effect of switching from premix to a glargine-based regimen on glycaemic control, body weight and insulin use in patients with type 1 or type 2 diabetes in a daily practice setting.

\section{Methods \\ Data source}

The data were sourced from a large national computerised medical record database known as The Health Improvement Network (THIN), which includes data from 211 UK primary care practices collected over a 15 year period from about 5 million patients, of whom 2.34 million were actively registered with a practice and prospectively followed [17]. The THIN database is not supported by any industrial sponsor, nor biased towards any particular disease group. THIN data on patient demographics, medical history, test results and drug treatments are collected in a non-interventional manner during daily record keeping within the general practice. To ensure confidentiality of patient information, the data are anonymised at the collection stage using encrypted identifiers for the physician and individual.

From data collected between July 2002 and December 2005 , as described previously $[18,19], 137,258$ patients were identified as diabetic based on a relevant medical diagnosis using the Read code system [20] or prescription of OADs. Diagnosis of diabetes was attributed in a stepwise manner. For those few patients who did not have a specific diagnosis of diabetes (but use of insulin), a diagnosis of type 2 diabetes was attributed if the patient had received any non-insulin, diabetes-related medication, otherwise type 1 diabetes was assumed. Overall, $90 \%$ of patients were identified as having a diagnosis of type 2 diabetes. Ethical approval for this analysis was obtained from the London Multiple Research Ethics Committee (Number 06/MRE02/32) before commencing data extraction.

Individuals were included in the current analysis if a) they had been prescribed premix for at least 12 months before switching to glargine and b) they continued glargine without a switch to another basal insulin for at least 12 months. Following a switch to glargine patients could receive OADs and/or boluses of prandial insulin in addition to basal glargine. Information on associated comorbidities including myocardial infarction, stroke, peripheral vascular disease, neuropathy, nephropathy, and retinopathy was also extracted. Use of analogue and human prandial insulins could not be distinguished from information collected.

\section{Design and outcome measures}

This was a retrospective, 24-month, non-randomised analysis. The principal analysis was glycaemic control measured using $\mathrm{HbA}_{1 \mathrm{c}}$. Measurements were performed locally in each centre and mean $\mathrm{HbA}_{1 \mathrm{c}}$ values were calculated every 3 months before and after switching insulin therapy using actual or linearly interpolated values. Although much of the UK is currently $\mathrm{HbA}_{1 \mathrm{c}}$ DCCT- 
aligned, and primary care practices use National Health Service hospital laboratories which are members of quality assurance schemes, the degree of standardisation at the time of data collection (2002-2006) is not known. However, our study depends on change in $\mathrm{HbA}_{1 \mathrm{c}}$ and will thus be less sensitive to differences in calibration between assays. Secondary analyses included mean change in weight $(\mathrm{kg})$ calculated as for $\mathrm{HbA}_{1 \mathrm{c}}$, mean change in prescribed daily insulin dose calculated as units prescribed divided by the number of days covered by the prescription, the proportion of patients using bolus prandial insulin, and the percentage of patients achieving defined $\mathrm{HbA}_{1 \mathrm{c}}$ levels. Self-reported episodes of hypoglycaemia were recorded by general practitioners during each 3 monthly interval.

\section{Statistical methods}

Linear interpolation of missing data was performed where a patient had at least 2 data measurements during each 12 month period (prior to and following switch) and data was not missing during two consecutive 3 monthly intervals. Unadjusted results for the principle $\left(\mathrm{HbA}_{1 \mathrm{c}}\right)$ and secondary analyses used linearly interpolated data and were summarised using descriptive statistics. For the unadjusted results the mean change during the 12 month prior to and following the switch was calculated. Comparisons were performed using paired t-tests. Graphical analyses were based on linearly interpolated data, which provides a clearer graphical interpretation of the results.

For the principle analysis of change in $\mathrm{HbA}_{1 \mathrm{c}}$ a multivariate analysis using actual patient data was performed. Actual patient data was preferred over interpolated values; multivariate models constructed using the later showing no appreciable effect on the model specification or statistical inference. Data was evaluated using multiple linear mixed regression analyses, adjusting for repeated measures per patient over time, with change in $\mathrm{HbA}_{1 \mathrm{c}}$ relative to time of insulin initiation as the dependent variable with the following pre-defined (fixed-effects) exploratory covariates; age, weight, sex, type of diabetes, number of OADs used before commencing insulin, number of OADs used in combination with insulin at initiation, disease duration, presence of hypoglycaemia and associated comorbidities during the study.

Multivariate models were developed with SPSS for Windows (version 8; SPSS, Chicago, IL, USA) using a backward stepwise approach; non-significant variables at the $5 \%$ level were excluded. Sensitivity analyses were performed to investigate the effect of baseline $\mathrm{HbA}_{1 \mathrm{c}}$ levels on treatment efficacy. Secondary endpoints and the percentage of patients achieving set $\mathrm{HbA}_{1 \mathrm{c}}$ levels were summarised descriptively.

\section{Results \\ Subjects and baseline characteristics}

A total of 528 patients, 183 (35\%) with type 1 diabetes and 345 (65\%) with type 2 diabetes, were included in the analysis (Table 1). Mean $\mathrm{HbA}_{1 \mathrm{c}}$ at baseline before switching was similar in each group (9.4\% and $9.3 \%$, respectively). Overall, 39\% of patients with type 1 diabetes and $21 \%$ with type 2 diabetes had received bolus insulin doses in the previous 12 months prior to the switch, whilst $0 \%$ and $38 \%$ of patients with type 1 and type 2 diabetes respectively were taking an OAD.

\section{Change in $\mathbf{H b A}_{\text {lc }}$}

Mean $\mathrm{HbA}_{1 \mathrm{c}}$ increased in the 12 months prior to the switch in both diabetic cohorts, by $0.21 \%$ (from $9.21 \%$ to $9.42 \%, \mathrm{p}>0.05)$ in the type 1 cohort and by $0.05 \%$ $(9.17 \%$ to $9.26 \%, \mathrm{p}>0.05)$ in the type 2 cohort (Figure 1A). 12 months after the switch, mean $\mathrm{HbA}_{1 \mathrm{c}}$ was significantly lower compared with baseline in each cohort, decreasing by $0.63 \%$ (from $9.42 \%$ to $8.79 \%, p=0.003$ ) in patients with type 1 diabetes and by $0.47 \%$ (from $9.26 \%$ to $8.79 \%, \mathrm{p}=0.0004$ ) in patients with type 2 diabetes (Figure $1 \mathrm{~B}$ ). The greatest decrease in mean $\mathrm{HbA}_{1 \mathrm{c}}$ was observed in the first 6 months following the switch to a glargine-based regimen. After adjustment for significant demographic and clinical covariates, including age, weight, baseline $\mathrm{HbA}_{1 \mathrm{c}^{\prime}}$ hypoglycaemia and concomitant use of OADs, the reduction in mean $\mathrm{HbA}_{1 \mathrm{c}}$ over 12 months of glargine treatment was $0.67 \%(\mathrm{p}<0.001)$ in the type 1 diabetes cohort and $0.53 \%$ in the type 2 diabetes cohort $(\mathrm{p}<0.001)$ (Table 2$)$. Sensitivity analyses showed that improvement in $\mathrm{HbA}_{1 \mathrm{c}}$ after switching to glargine was positively correlated with baseline $\mathrm{HbA}_{1 \mathrm{c}}$. Patients with baseline $\mathrm{HbA}_{1 \mathrm{c}} \geq 10 \%$ had the greatest reduction in mean $\mathrm{HbA}_{1 \mathrm{c}}(-1.7 \%$ in the type 1 diabetes cohort and $-1.2 \%$ in the type 2 diabetes cohort) (Table 2 ). In each cohort, the reduction in $\mathrm{HbA}_{1 \mathrm{c}}$ did not differ significantly by sex, age or weight (data not shown).

\section{Proportion of patients reaching $\mathbf{H b A}_{\text {Ic }}$ levels}

Overall, $35 \%$ of patients achieved a $\mathrm{HbA}_{1 \mathrm{c}}$ level of $7 \%$ within 12 months of the switch. 32\% of the type 1 cohort and $33 \%$ of the type 2 cohort achieved a reduction in $\mathrm{HbA}_{1 \mathrm{c}} \geq 1 \%$.

\section{Episodes of hypoglycaemia}

During the 12 months prior to the switch from premix to glargine, 105 hypoglycaemic episodes were reported by the patients with type 1 diabetes $(0.57$ episodes per patient/year), while 207 episodes were reported by patients with type 2 diabetes ( 0.60 episodes per patient/ year). After switching to glargine, the respective data were 194 episodes for the patients with type 1 diabetes (1.06 episodes per patient/year) and 406 episodes for the 
Table I: Baseline characteristics of patients switching from premix to glargine

\begin{tabular}{|c|c|c|}
\hline & Type I diabetes & Type 2 diabetes \\
\hline $\mathrm{n}(\%)$ & $183(35)$ & $345(65)$ \\
\hline$\%$ male & 53.0 & 53.0 \\
\hline Age (years)* & $22.9 \pm 15.5$ & $55.8 \pm 16.6$ \\
\hline Weight $(\mathrm{kg})^{*}$ & $67.7 \pm 2.7$ & $85.3 \pm 2.2$ \\
\hline Baseline $\mathrm{HbA}_{\mathrm{Ic}} * \dagger$ & $9.4 \pm 1.6$ & $9.3 \pm 1.5$ \\
\hline Duration of diabetes (years) $\ddagger$ & $7.9 \pm 8.7$ & $8.1 \pm 6.7$ \\
\hline Number of co-morbidities§ & $2.5 \pm 2.4$ & $2.4 \pm 1.9$ \\
\hline Premix insulin only (\%) & $61 \%$ & $48 \%$ \\
\hline Premix insulin with OAD (\%) & $0 \%$ & $38 \%$ \\
\hline Premix + short acting insulin (\%) & $25 \%$ & $16 \%$ \\
\hline Premix + basal insulin (\%) & $8 \%$ & $5 \%$ \\
\hline Premix + short acting + basal insulin (\%) & $2 \%$ & $3 \%$ \\
\hline Premix + other insulin +/-OADs (\%) & $0 \%$ & $2 \%$ \\
\hline OADs per patient before starting insulin therapy*I & - & $0.4 \pm 0.5$ \\
\hline \multicolumn{3}{|l|}{ Hypoglycaemia episodes in 3 month period*\| } \\
\hline No. episodes & 38 & 72 \\
\hline Mean no. episodes per patient & 0.21 & 0.21 \\
\hline
\end{tabular}

$\mathrm{OAD}=$ oral antidiabetic drug; $\mathrm{HbA}_{\mathrm{Ic}}=$ glycated haemoglobin. Data are mean $\pm \mathrm{SD}$ unless indicated.

*Significant variables investigated in multivariate analysis.

†Data missing for 29 patients with type I diabetes and 27 patients with type 2 diabetes.

$\ddagger$ Data missing for 2 patients with type I diabetes and 5 patients with type 2 diabetes.

$\S$ Includes myocardial infarction, stroke, peripheral vascular disease, neuropathy, nephropathy and retinopathy.

TNumber of oral diabetic treatments (e.g. metformin, sulfonylureas) prescribed prior to commencing insulin.

||Hypoglycaemic episodes reported during the 3 month period prior to switch. Episodes reported in 27 patients with type I diabetes and 44

patients with type 2 diabetes.

patients with type 2 diabetes (1.18 episodes per patient/ year) during the following 12 months.

\section{Change in use of boluses, total insulin usage and weight}

The majority of patients switched from premix to a basalbolus glargine regimen. Significant increases in the mean use of bolus regimens in both diabetic cohorts were recorded (from $24.6 \%$ on premix to $95.1 \%$ on glargine in the type 1 cohort $[\mathrm{p}<0.001]$, and from $16.2 \%$ to $73.9 \%$ in the type 2 cohort [p $<0.001]$, Figure 1C). Switching from premix to glargine was associated with an increase in the mean total (glargine + prandial) daily insulin dose in the type 2 diabetes cohort (from $0.67 \pm 1.35 \mathrm{U} / \mathrm{Kg}$ to 0.88 $\pm 1.33 \mathrm{U} / \mathrm{Kg}, \mathrm{p}<0.001$ ) but a slight decrease in the type 1 cohort (from $1.04 \pm 2.51 \mathrm{U} / \mathrm{Kg}$ to $0.98 \pm 2.58 \mathrm{U} / \mathrm{Kg}$, p < 0.001 ) (Figure 1D). The small initial increase in the first 6 months after the switch in each cohort may be due a "stock building effect", whereby patients are initially prescribed additional insulin doses to allow them to store a security stock when starting the treatment with their new insulin. The use of OADs remained unchanged after the switch, with quarterly estimates indicating that between

Table 2: Adjusted $\mathrm{HbA}_{\mathrm{Ic}}$ reduction over 12 month period in patients switching from premix to glargine*

\begin{tabular}{|c|c|c|c|c|c|c|}
\hline \multirow[t]{2}{*}{ Variable } & \multicolumn{3}{|c|}{ Type I $(n=183)$} & \multicolumn{3}{|c|}{ Type $2(n=345)$} \\
\hline & No. & $\Delta \mathbf{H b A}_{\mathrm{Ic}}(\%)$ & p-value $\nmid$ & No. & $\Delta \mathbf{H b A}_{\mathrm{Ic}}(\%)$ & p-value $\nmid$ \\
\hline Overall & 183 & -0.67 & $<0.001$ & 345 & -0.53 & $<0.001$ \\
\hline \multicolumn{7}{|c|}{ By baseline $\mathrm{HbA}_{\mathrm{Ic}}$ level } \\
\hline$\geq 7 \%$ & 151 & -0.67 & $<0.001$ & 306 & -0.56 & $<0.001$ \\
\hline$\geq 8 \%$ & 128 & -0.80 & $<0.001$ & 255 & -0.68 & $<0.001$ \\
\hline$\geq 9 \%$ & 86 & -1.06 & $<0.001$ & 169 & -0.84 & $<0.001$ \\
\hline$\geq 10 \%$ & 46 & -1.74 & $<0.001$ & 88 & -1.20 & $<0.001$ \\
\hline
\end{tabular}

$\mathrm{OAD}=$ oral antidiabetic drugs; $\mathrm{HbA}_{\mathrm{Ic}}=$ glycated haemoglobin.

*Adjusted for demographic and clinical covariates including age, weight, hypoglycaemia, concomitant use of OADs and baseline HbA $\mathrm{I}_{\mathrm{Ic}}$ (in the 3 months prior to insulin initiation).

$\nmid \mathrm{t}$-values by the paired $\mathrm{t}$-test for difference in mean $\mathrm{HbA}_{\mathrm{Ic}}$ following switch from premix to glargine. 
A

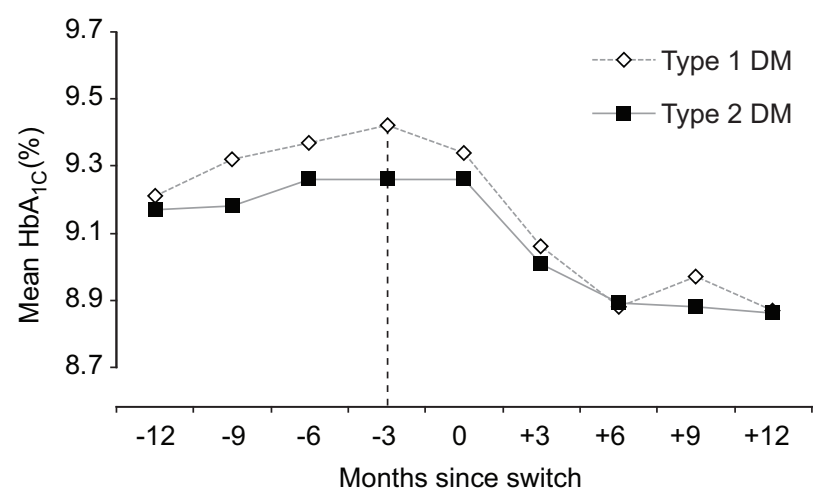

B

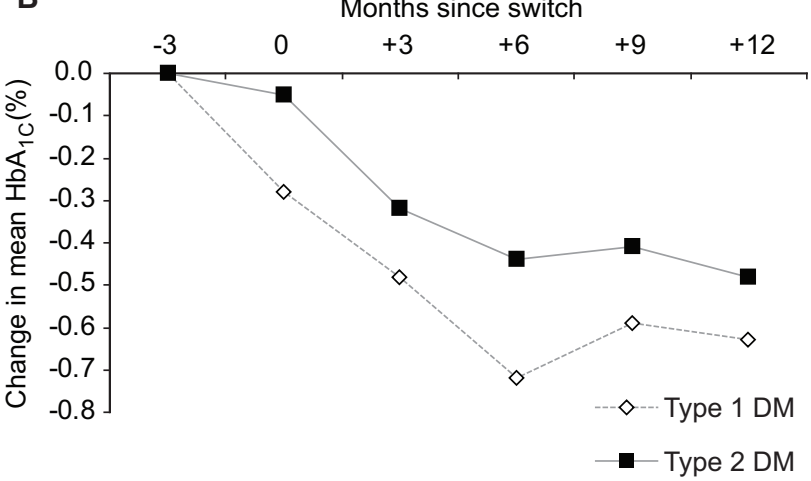

C

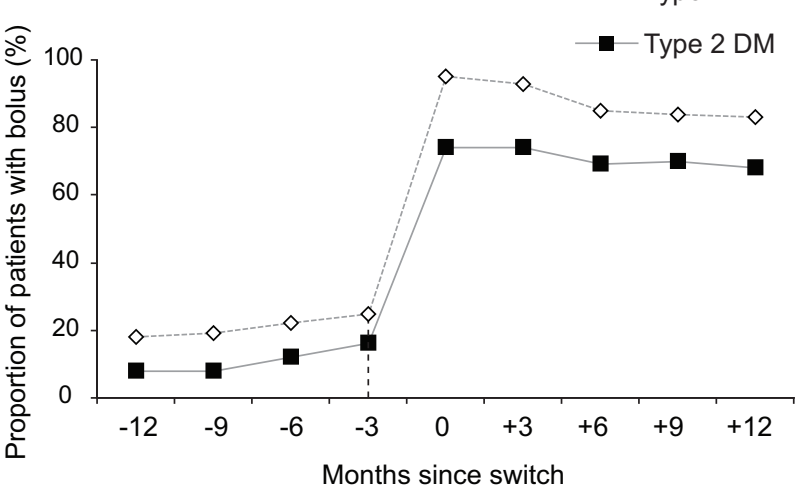

D

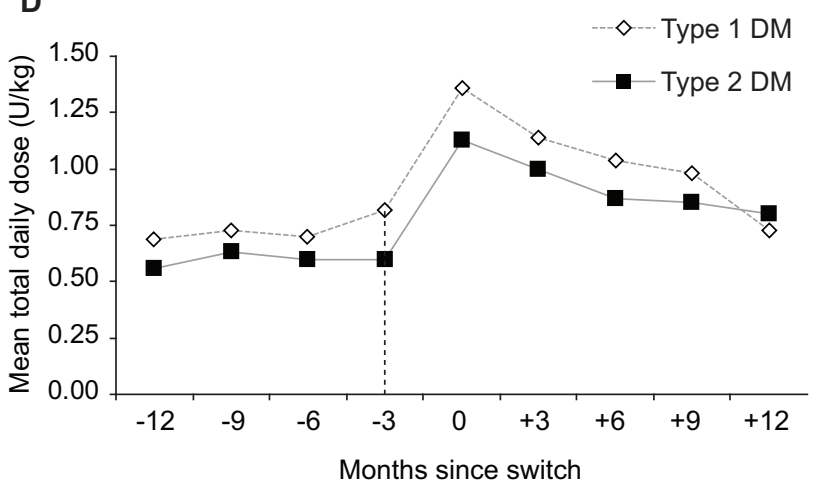

Figure I

Mean $\mathrm{HbA}_{\mathrm{lc}} \mathrm{I} 2$ months before and after switching from premix to glargine (A), mean change in $\mathrm{Hb} \mathrm{A}_{\mathrm{lc}}$ after switch (B), mean use of bolus insulin before and after switch (C) and mean total daily insulin dose before and after switch (D) (unadjusted data). The last measurement for premix is at -3 months (indicated by vertical dotted line). During period $-12 \mathrm{~m}$ to $-3 \mathrm{~m}$ patients are taking premix only. During the 3 month switch time point ( 0 months) patients may be prescribed premix and glargine. During period $+3 \mathrm{~m}$ to $+12 \mathrm{~m}$ patients are only prescribed glargine ( \pm prandial boluses). Linearly interpolated data were used to graphically depict the change in each parameter. Linearly interpolated data affords a clearer graphical interpretation but may bias estimates of variance; as such error bars ( $95 \%$ confidence intervals for the means) are not reported. Total daily insulin dose was calculated according to the number of units prescribed divided by the number of days covered by the prescription.

$34 \%$ and $37 \%$ of patients received OADs. There was no significant change in weight in the type 2 cohort (mean $+0.3 \mathrm{~kg}$, from $85.3 \pm 2.2 \mathrm{~kg}$ to $85.6 \pm 2.6 \mathrm{~kg}, \mathrm{p}>0.05$ ) with a moderate increase in type 1 patients (mean $+3.7 \mathrm{~kg}$, from $67.6 \pm 2.7 \mathrm{~kg}$ to $71.3 \pm 3.5 \mathrm{~kg}, \mathrm{p}>0.05)$.

\section{Discussion}

The results from this analysis show that in everyday clinical practice, switching to a basal-bolus glargine-based insulin regimen improves glycaemic control in patients with type 1 or type 2 diabetes inadequately controlled on a premix-based insulin regimen. The overall mean decrease in $\mathrm{HbA}_{1 \mathrm{c}}$ was $0.67 \%$ among type 1 patients and $0.53 \%$ among type 2 patients observed 12 months after switching to a glargine-based regimen.
These findings are supported by data from other observational studies in patients with type 2 diabetes switching from premix to glargine-based regimen [14-16] and by a randomised comparison of a premix-based regimen versus a glargine-based regimen in type 2 diabetic patients previously treated with a glargine-based regimen plus OADs [21]. In this later study, the difference in $\mathrm{HbA}_{1 \mathrm{c}}$ change after 6 months of treatment was $0.22 \%$ in favour of the glargine-based regimen, approximately half the decrease noted after 12 months in the type 2 patient cohort for our study.

Additionally, as far as we are aware, this analysis also provides the first evidence of a similar benefit in patients with type 1 diabetes. Sensitivity analyses showed that improve- 
ment in $\mathrm{HbA}_{1 \mathrm{c}}$ was greatest in patients with the poorest glycaemic control at baseline (mean increase of $1.2 \%$ to $1.7 \%$ in patients with baseline $\mathrm{HbA}_{1 \mathrm{c}}$ levels $\geq 10 \%$ ), with the magnitude of improvement equivalent to that observed in studies of patients newly commencing insulin therapy [22]. The United Kingdom Prospective Diabetes Study showed that a $1 \%$ reduction in $\mathrm{HbA}_{1 \mathrm{C}}$ was associated with a $14 \%$ reduction in myocardial infarction, a $14 \%$ reduction in all-cause mortality and a $37 \%$ reduction in microvascular complications [23]. Therefore, the reduction in $\mathrm{HbA}_{1 \mathrm{C}}$ of 0.5 to $0.7 \%$ observed in the overall population and $\geq 1 \%$ in the sensitivity analysis, achieved by switching to an insulin glargine-based regimen can be considered clinically meaningful as these results may translate to clinical outcomes benefits in the longer-term.

A number of features of this analysis strengthen our findings. Patients included in the analysis had frequent (at least 3-monthly) follow-up assessment over an extended period (12 months) before and after switching. Glycaemic control was evaluated using a uniform, valid, reliable and widely used measure $\left(\mathrm{HbA}_{1 \mathrm{c}}\right)$, which is of relevance to a real-life clinical practice. Additionally, analysis of changes in clinical outcomes was assessed by means of linear interpolation for missing data and multiple regression techniques to account for factors that may influence the change in $\mathrm{HbA}_{1 \mathrm{c}}$. In particular, the multivariate model attempted to account for the significant increases in the use of bolus regimens in patients receiving glargine.

However, we do acknowledge a number of limitations. First, we recognise that retrospective observational studies do not provide the same robust level of evidence as randomised controlled trials. Countering this, it should be noted that results from such randomised evaluations may not translate readily to daily practice for a number of reasons [24,25]. Patients treated within clinical trials generally receive a higher standard of care than that provided in daily clinical practice $[26,27]$ and they typically have restricted inclusion criteria in selected populations which are generally not representative of those patients treated in clinical practice. Moreover, findings from a single randomised controlled trial can be subject to substantial population bias which can skew results. These points argue for the use of observational studies (such as the current analysis), which are generally well equipped to describe actual health outcomes in a real-life clinical setting. Health technology assessment bodies, including the National Institute of Clinical Excellence in the UK, increasingly seek data outside the setting of randomised controlled trials [28]. However, we do acknowledge that the level of data collection in our analysis did not permit investigation of various factors that may have influenced our findings, including certain background characteristics (e.g. ethnicity, body mass index) of the patient population [29-31], dosing regimen (once vs. twice daily) [32] increased patient compliance following the switch (e.g. higher number of general practice visits) and timing of administration of glargine (morning vs. bedtime) [33,34]. The low number of patients included in the study did not permit certain subgroup analyses such as the influence of prandial boluses on glycaemic control in type 2 patients switched onto a glargine-based insulin regimen [16].

Second, it was not possible to reliably assess data concerning hypoglycaemic episodes in patients who switch from a premix-based regimen to a glargine-based regimen. A lack of consistency in recording these data in the THIN database meant that there is strong likelihood that we underestimated the real incidence of hypoglycaemia and only captured the most severe episodes. The incidence of hypoglycaemia may also reflect the self-reporting methods used, as patients and physicians were not requested to provide specific details of each episode. The limitations of the database also did not allow assessment of the severity or nature (e.g. nocturnal) of hypoglycaemic episodes before and after the switch. A higher number of hypoglycaemic episodes were noted after the switch from premix to glargine. Should this trend be real, the significant improvement in glycaemic control observed with glargine in both diabetic cohorts and the higher use of bolus regimens in both diabetic cohorts is likely to make patients more susceptible to episodes of hypoglycaemia. The reason for the slightly higher mean number of hypoglycaemic episodes per patient observed in the type 2 cohort compared with type 1 diabetic cohort is not known and not in keeping with previous observations.

Third, the decision to switch insulin treatment was not based on a standard treatment algorithm but instead on the clinical judgement of individual clinicians, thereby introducing a subjective bias in the management of patients in each cohort. Furthermore, as data in this analysis were included from a large number of general practice units, this may had led to further heterogeneity in the data. However, it is possible that the extended period of assessment (12 months) before and after the switch may have limited the potential for introduction of bias in our analysis. In respect of this point, it is reassuring that our findings are supported by other analyses from different populations and geographic locations using different methods of collection of information [14-16]. Finally, as with any observational study there may be concerns about missing data. In the current study, interpolated $\mathrm{HbA}_{1 \mathrm{c}}$ data were available for $87 \%$ of patients during the months preceding and immediately following the switch, decreasing to $65 \%$ of patients during the 12 months after the switch. Overall, interpolated $\mathrm{HbA}_{1 \mathrm{c}}$ data was used in $60 \%$ of patients. However, the main analysis performed in our 
study was based on the adjusted change in $\mathrm{HbA}_{1 \mathrm{c}}$ which only used actual and complete data values.

While findings from this analysis suggest that the use of an glargine-based regimen possibly combining glargine with either OADs or prandial insulin may be a useful alternative for improving glycaemic control when other insulin therapies have failed, there is evidence that glycaemic control is still suboptimal in UK general practice. In our analysis, two-thirds of patients remained above a $\mathrm{HbA}_{1 \mathrm{c}}$ level of $7 \%$, indicating that a large proportion of patients do not reach preferred target levels. This could indicate that the initiation of insulin was possibly too late and that additional treatment strategies are needed. This may include more aggressive titration with insulin glargine (in the current analysis glargine treatment had no significant effect on weight despite a moderate increase for the type 1 patients suggesting suboptimal treatment), greater use of OAD therapy in patients with type 2 diabetes (only $38 \%$ were receiving OAD therapy at baseline and 35\% at 12 months), additional doses of prandial insulin and the use of educational programs [16,35-37].

\section{Conclusion}

This retrospective analysis shows that switching from premix to a basal-bolus glargine-based insulin regimen improves glycaemic control substantially. Given the caveats associated with retrospective data collection, our findings suggest that this approach may be useful in a clinical practice setting for the management of patients in whom premix is suboptimally effective or poorly tolerated.

\section{Abbreviations}

$\mathrm{HbA}_{1 \mathrm{c}}$ : glycated haemoglobin; OADs: oral antidiabetic drugs; THIN: The Health Improvement Network.

\section{Competing interests}

All authors were consultants to Sanofi-Aventis, had full access to all the data in the study and took responsibility for the decision to submit for publication.

\section{Authors' contributions}

PS and JG performed the statistical analyses and drafted the manuscript. JRP, APT, AL, and PM were involved in study design, coordination and data acquisition. All authors have read and approved the final manuscript.

\section{Acknowledgements}

The contributions of the investigators and study coordinators who participate in the THIN study are greatly appreciated. This study was sponsored by Sanofi-Aventis, Paris, France.

Preliminary results of this study were presented as a poster at the $\mathrm{I}^{\text {th }}$ Annual ISPOR European Congress, Athens, Greece, 8-I I November 2008.

\section{References}

I. National Institute for Health and Clinical Excellence: The management of type 2 diabetes (update). (Clinical guideline 66.) 2008 [http://www.nice.org.uk/Guidance/CG66]. London: NICE

2. National Institute for Health and Clinical Excellence: Diagnosis and management of type I diabetes in children, young people and adults. Clinical guideline 152004 [http://www.nice.org.uk/guid ance/index.jsp?action=byID\&o=10944]. London: NICE

3. IDF Clinical Guidelines Task Force: Global Guideline for Type 2 Diabetes: recommendations for standard, comprehensive, and minimal care. Diabet Med 2006, 23:579-593.

4. AACE Diabetes Mellitus Clinical Practice Guidelines Task Force: American Association of Clinical Endocrinologists medical guidelines for clinical practice for the management of diabetes mellitus. Endocr Pract 2007, I 3(Suppl I): I-68.

5. American Diabetes Association: Standards of medical care in diabetes-2008. Diabetes Care 2008, 3 I (SuppI I):SI 2-54.

6. Department of Health: Diabetes National Service Framework Guidelines. [http://www.dh.gov.uk/en/Healthcare/NationalService Frameworks/Diabetes/index.htm].

7. Nathan DM, Buse JB, Davidson MB, Ferrannini E, Holman RR, Sherwin $R$, Zinman B: Management of hyperglycemia in type 2 diabetes: $A$ consensus algorithm for the initiation and adjustment of therapy: a consensus statement from the American Diabetes Association and the European Association for the Study of Diabetes. Diabetes Care 2008, 3 I : I- I I.

8. The Diabetes Control and Complications Trial Research Group: The effect of intensive treatment of diabetes on the development and progression of long-term complications in insulindependent diabetes mellitus. NEJM 1993, 329:977-986.

9. UK Prospective Diabetes Study Group: Effect of intensive bloodglucose control with metformin on complications in overweight patients with type 2 diabetes UK Prospective Diabetes Study (UKPDS) Group. (UKPDS 34). Lancet 1998, 352:854-865.

10. UK Prospective Diabetes Study (UKPDS) Group: Intensive bloodglucose control with sulphonylureas or insulin compared with conventional treatment and risk of complications in patients with type 2 diabetes (UKPDS 33). UK Prospective Diabetes Study (UKPDS) Group. Lancet 1998, 352:837-853.

II. Roach P, Trautmann M, Arora V, Sun B, Anderson JH Jr: Improved postprandial blood glucose control and reduced nocturnal hypoglycemia during treatment with two novel insulin lispro-protamine formulations, insulin lispro mix 25 and insulin lispro mix50. Mix50 Study Group. Clin Ther 1999, 2 I:523-534.

12. Heinemann L, Linkeschova R, Rave K, Hompesch B, Sedlak M, Heise : Time-action profile of the long-acting insulin analog insulin glargine (HOE90I) in comparison with those of NPH insulin and placebo. Diabetes Care 2000, 23:644-649.

13. Janka HU, Plewe G, Riddle MC, Kliebe-Frisch C, Schweitzer MA, YkiJarvinen $H$ : Comparison of basal insulin added to oral agents versus twice-daily premixed insulin as initial insulin therapy for type 2 diabetes. Diabetes Care 2005, 28:254-259.

14. Hammer $\mathrm{H}$, Klinge A: Patients with type 2 diabetes inadequately controlled on premixed insulin: effect of initiating insulin glargine plus oral antidiabetic agents on glycaemic control in daily practice. Int J Clin Pract 2007, 6 I:2009-2018.

15. Schiel R, Muller UA: Efficacy and treatment satisfaction of once-daily insulin glargine plus one or two oral antidiabetic agents versus continuing premixed human insulin in patients with type 2 diabetes previously on long-term conventional insulin therapy: the Switch pilot study. Exp Clin Endocrinol Diabetes 2007, I | 5:627-633.

16. Davies M, Sinnassamy P, Storms F, Gomis R: Insulin glargine-based therapy improves glycemic control in patients with type 2 diabetes sub-optimally controlled on premixed insulin therapies. Diabetes Res Clin Pract 2008, 79:368-375.

17. Bourke A, Dattani H, Robinson M: Feasibility study and methodology to create a quality-evaluated database of primary care data. Inform Prim Care 2004, I 2: I7I-I77.

18. Currie C], Poole CD, Tetlow T, Holmes P, McEwan P: The outcome of care in people with type $I$ and type 2 diabetes following switching to treatment with either insulin glargine or insulin detemir in routine general practice in the UK: A retrospective database analysis. Curr Med Res Opin, Suppl 2007, 23:S33-S39. 
19. Poole CD, Tetlow T, McEwan P, Holmes P, Currie C): The prescription cost of managing people with type $I$ and type 2 diabetes following initiation of treatment with either insulin glargine or insulin detemir in routine general practice in the UK: A retrospective database analysis. Curr Med Res Opin, Suppl 2007, 23:S4I-S48.

20. Brown PJ, Warmington V, Laurence M, Prevost AT: Randomised crossover trial comparing the performance of Clinical Terms Version 3 and Read Codes 5 byte set coding schemes in general practice. BMJ 2003, 326: I I 27.

21. Rosenstock J, Ahmann AJ, Colon G, Scism-Bacon J, Jiang H, Martin S: Advancing insulin therapy in type 2 diabetes previously treated with glargine plus oral agents: prandial premixed (insulin lispro protamine suspension/lispro) versus basal/ bolus (glargine/lispro) therapy. Diabetes Care 2008, 3I:20-25.

22. Schreiber SA, Haak T: Insulin glargine benefits patients with type 2 diabetes inadequately controlled on oral antidiabetic treatment: an observational study of everyday practice in I 2,216 patients. Diabetes Obes Metab 2007, 9:31-38.

23. Stratton IM, Adler AI, Neil HA, Matthews DR, Manley SE, Cull CA, Hadden D, Turner RC, Holman RR: Association of glycaemia with macrovascular and microvascular complications of type 2 diabetes (UKPDS 35): prospective observational study. BMJ 2000, 32 I :405-4I 2.

24. Benson K, Hartz AJ: A comparison of observational studies and randomized, controlled trials. NEJM 2000, 342:|878-|886.

25. Concato J, Shah N, Horwitz RI: Randomized, controlled trials, observational studies, and the hierarchy of research designs. NEJM 2000, 342:1887-1892

26. Cramer JA, Pugh MJ: The influence of insulin use on glycemic control: How well do adults follow prescriptions for insulin? Diabetes Care 2005, 28:78-83.

27. Lee WC, Balu S, Cobden D, Joshi AV, Pashos CL: Medication adherence and the associated health-economic impact among patients with type 2 diabetes mellitus converting to insulin pen therapy: an analysis of third-party managed care claims data. Clin Ther 2006, 28: 17/2-1725.

28. National Institute for Health and Clinical Excellence: Guide to the methods of technology appraisal. 2008 [http://www.nice.org.uk/ media/B52/A7/TAMethodsGuideUpdated]une2008.pdf]. London: NICE

29. Benedetti M, Humburg E, Dressler A, Ziemen M: A one-year, randomised, multicentre trial comparing insulin glargine with NPH insulin in combination with oral agents in patients with type 2 diabetes. Horm Metab Res 2003, 35:189-196.

30. Gallen I, Carter C: Prospective audit of the introduction of insulin glargine (Lantus) into clinical practice in type I diabetes. Pract Diab Int 2004, 2 I: I 10-1 I4.

31. Erickson TN, Devine EB, O'Young TS, Hanson LJ, French B, Brennan $C$ : Effect of switching medically vulnerable patients with uncontrolled diabetes from isophane insulin human to insulin glargine. Am J Health Syst Pharm 2006, 63:I862-I87I.

32. Albright ES, Desmond R, Bell DS: Efficacy of conversion from bedtime NPH insulin injection to once- or twice-daily injections of insulin glargine in type I diabetic patients using basal/bolus therapy. Diabetes Care 2004, 27:632-633.

33. Hamann A, Matthaei S, Rosak C, Silvestre L: A randomized clinical trial comparing breakfast, dinner, or bedtime administration of insulin glargine in patients with type I diabetes. Diabetes Care 2003, 26:1738-1744.

34. Fritsche A, Schweitzer MA, Haring HU: Glimepiride combined with morning insulin glargine, bedtime neutral protamine hagedorn insulin, or bedtime insulin glargine in patients with type 2 diabetes. A randomized, controlled trial. Ann Intern Med 2003, 138:952-959.

35. Raccah D, Bretzel RG, Owens D, Riddle M: When basal insulin therapy in type 2 diabetes mellitus is not enough-what next? Diabetes Metab Res Rev 2007, 23:257-264.

36. Schreiber SA, Russmann A: The effects of insulin glargine treatment and an educational programme on glycaemic contro in type 2 diabetes patients in clinical practice. Curr Med Res Opin 2006, 22:335-341.

37. Schreiber SA, Russmann A: Long-term efficacy of insulin glargine therapy with an educational programme in type I diabetes patients in clinical practice. Curr Med Res Opin 2007 , 23:3|3|-3|36
Publish with Bio Med Central and every scientist can read your work free of charge

"BioMed Central will be the most significant development for disseminating the results of biomedical research in our lifetime. "

Sir Paul Nurse, Cancer Research UK

Your research papers will be:

- available free of charge to the entire biomedical community

- peer reviewed and published immediately upon acceptance

- cited in PubMed and archived on PubMed Central

- yours - you keep the copyright 